\title{
Remote sensing and modeling of energetic electron precipitation into the lower ionosphere using VLF/LF radio waves and field aligned current data
}

\author{
E. D. Schmitter ${ }^{1, \dagger}$ \\ ${ }^{1}$ University of Applied Sciences Osnabrueck, 49076 Osnabrueck, Germany \\ ${ }^{\dagger}$ deceased, 25 March 2015
}

Correspondence to: M. Förster (mfo@gfz-potsdam.de)

Received: 1 November 2014 - Revised: 30 April 2015 - Accepted: 30 April 2015 - Published: 3 November 2015

\begin{abstract}
A model for the development of electron density height profiles based on space time distributed ionization sources and reaction rates in the lower ionosphere is described. Special attention is payed to the definition of an auroral oval distribution function for energetic electron energy input into the lower ionosphere based on a Maxwellian energy spectrum. The distribution function is controlled by an activity parameter which is defined proportional to radio signal amplitude disturbances of a VLF/LF transmitter. Adjusting the proportionality constant allows to model precipitation caused VLF/LF signal disturbances using radio wave propagation calculations and to scale the distribution function. Field aligned current (FAC) data from the new Swarm satellite mission are used to constrain the spatial extent of the distribution function. As an example electron precipitation bursts during a moderate substorm on the 12 April 2014 (midnight-dawn) are modeled along the subauroral propagation path from the NFR/TFK transmitter $(37.5 \mathrm{kHz}$, Iceland) to a midlatitude site.
\end{abstract}

\section{Introduction}

The lower ionosphere $(60-85 \mathrm{~km}$ height) is forced from above by extreme UV, especially Lyman $\alpha$, solar flare Xrays and energetic particle precipitation (electrons $\gtrsim 30 \mathrm{keV}$, protons $\gtrsim 4 \mathrm{MeV}$, lower energetic particles do not penetrate so deeply). Forcing from below takes place via tides, gravity- and planetary waves, but also lightning electromagnetic pulses and upward discharges (Fig. 1). Ionization by particles not only directly enhances the local electron/ion

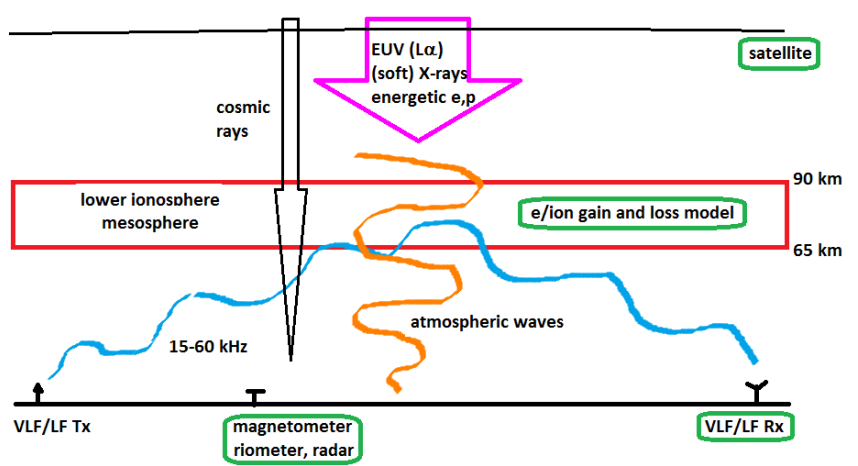

Figure 1. Forcing of the lower ionosphere/mesosphere and remote sensing instrumentation.

density but also leads to the formation of HOx and NOx molecules. The latter family is rather long living and by vertical transport also reaches the stratosphere where it catalytically affects the ozone budget, especially in the polar region (Clilverd et al., 2007; Salmi et al., 2011). This is one example of the strong coupling of the different ionospheric and atmospheric layers. Very low frequency and low frequency (VLF/LF) electromagnetic radiation from man made transmitters $(15-60 \mathrm{kHz})$, but also from lightning, propagates mainly between ground and the lower ionosphere. The propagation conditions are strongly affected by the conductivity of the lower ionosphere which is proportional to the quotient of the electron density and collision frequency height profiles. Remote VLF/LF sensing therefore since decades proves as an inexpensive and reliable way to assess forcing processes in this layer, also with regard to auroral pre- 


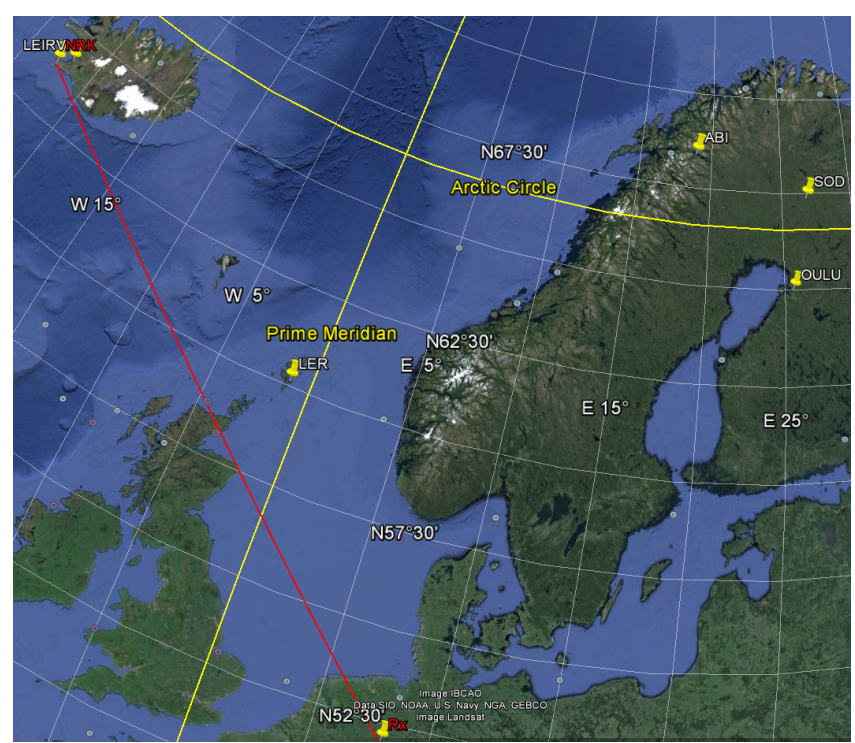

Figure 2. The monitored propagation path (red line; transmitter: NRK, receiver: Rx). Also indicated: magnetometers LEIRV: Leirvogur, LER: Lerwick; riometers: ABI, SOD, OULU: Abisko, Sodankyla, Oulu.

cipitation activity (Cummer et al., 1996, 1998). During the last years we have developed a modeling scheme that allows to assess ionospheric forcing parameters from VLF/LF amplitude and phase recordings of distant Minimum Shift Keying (MSK) transmitters (Schmitter, 2010, 2011, 2012, 2013, 2014). As the amplitude of these transmissions is constant, any observed variations are caused along the propagation path. The monitored propagation path from the VLF/LF transmitter with the call sign NRK/TFK $\left(37.5 \mathrm{kHz}, 63.9^{\circ} \mathrm{N}\right.$, $22.5^{\circ} \mathrm{W}$, Iceland) to our receiver site $52^{\circ} \mathrm{N}, 8^{\circ} \mathrm{E}$ (NW Germany, $2210 \mathrm{~km}$ ) starts in the subauroral domain and extends to midlatitudes (Fig. 2). In this paper we extend our model to include forcing by energetic electrons. The penetration depths of energetic electrons are shown in Fig. 3. Assuming a Maxwellian electron energy distribution electrons with a folding energy exceeding $30 \mathrm{keV}$ have their ionization maximum in the lower ionosphere $(\lesssim 85 \mathrm{~km})$ strongly affecting VLF/LF propagation. Riometers monitor cosmic noise absorption at about $90-100 \mathrm{~km}$ height and in this respect they are also sensitive to electron precipitation, however with regard to lower energies $(\sim 10 \mathrm{keV}$, i.e. auroral electrons). Magnetometer recordings reflect the current variations caused by geomagnetic storm/substorm conditions which often are accompanied by particle precipitation. Large scale energetic electron precipitation modify the auroral electrojet and lead to variations of the AL index. In this way ground based observations by riometers and magnetometers at proper sites yield important additional information with regard to the identification of energetic electron precipitation along the VLF/LF propagation path. The sources of the pre-

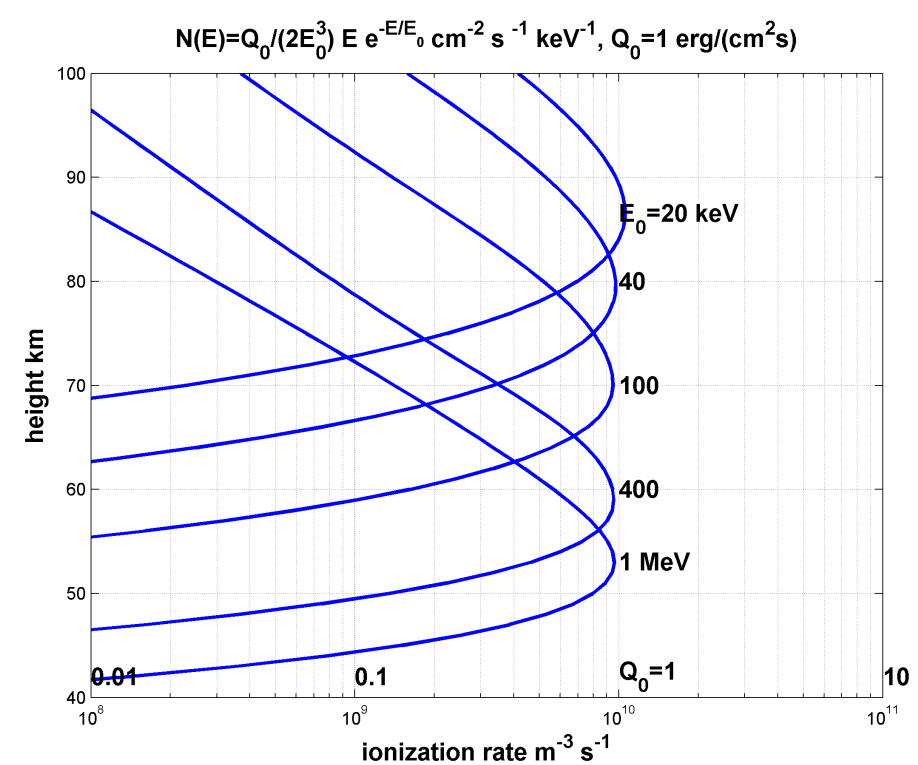

Figure 3. Ionization rate vs. height profile for Maxwellian electrons of different folding energies $E_{0}$ (normalized to the energy flux rate $Q_{0}=1 \mathrm{~mW} \mathrm{~m}^{-2}=1 \mathrm{erg} \mathrm{cm}^{-2} \mathrm{~s}^{-1}=10^{-7} \mathrm{~J} \mathrm{~cm}^{-2} \mathrm{~s}^{-1}=$ $\left.6.25 \cdot 10^{8} \mathrm{keV} \mathrm{cm}^{-2} \mathrm{~s}^{-1}\right)$. Atmospheric model: COSPAR International Reference Atmosphere (CIRA86, June, $50^{\circ} \mathrm{N}$ ).

cipitation are the radiation belts (Thorne, 1974; Carson et al., 2012; Thorne et al., 2013). So, for a detailed characterization of precipitation, satellite data are indispensable, even if a specific domain (e.g. around the VLF/LF propagation path) cannot be monitored continuously.

Mapping down electric and magnetic field measurements and derived data (field aligned currents, FACs, Ritter et al., 2013) from the Swarm satellites yields important information for the assessment of the energy input into the ionosphere, particularly with regard to the path and spatial extent of particle precipitation as well as the acceleration mechanisms. At least a part of the energetic electron precipitation is coupled to the midnight-dawn region 2 (equatorward) currents and the dusk-midnight region 1 (poleward) currents (Ohtani et al., 2010). So it may be expected, that the subauroral VLF propagation path is mainly affected by energetic electron precipitation coupled to region 2 (equatorward) field aligned currents, however compare the discussion of measured FAC data with regard to this simple picture in Sect. 5. In this paper we describe the VLF remote sensing procedure followed by the discussion of our model for the calculation of the electron density profiles, especially with regard to forcing events like electron precipitation. After the description of the VLF radio wave propagation calculations we discuss an example event: electron precipitation bursts during a moderate substorm on the 12 April 2014 (midnight-dawn) and the derivation of the precipitation energy input along a VLF propagation path in space and time from VLF data as well as using field aligned current data from the new Swarm satellite mission (launch: 
22 November 2013). This mission was designed to measure the magnetic signals from Earth's core, mantle, crust, oceans, ionosphere and magnetosphere. It consists of a constellation of three identical satellites in low polar orbits: two of them orbit side-by-side, descending from an initial altitude of 460 $300 \mathrm{~km}$ over 4 years; the third maintains an altitude of about $530 \mathrm{~km}$. Each satellite carries a vector field magnetometer, an absolute scalar magnetometer and an electric field instrument (for a complete description see www.esa.int). In our paper the field aligned current (FAC) data, a Level 2 product generated from the magnetic field data, are used.

\section{Remote sensing}

Remote sensing of lower ionosphere conditions (bottomside sounding) by monitoring low and very low frequency radio signal propagation has been a well known method for several decades. MSK (Minimum Shift Keying) transmitters prove useful in this respect because of their constant amplitude emissions. We have analyzed the signal amplitude and phase variations of the NRK/TFK transmitter $\left(37.5 \mathrm{kHz}, 63.9^{\circ} \mathrm{N}\right.$, $22.5^{\circ} \mathrm{W}$, Iceland) received at a midlatitude site $\left(52^{\circ} \mathrm{N}, 8^{\circ} \mathrm{E}\right)$ with a great circle distance of $2210 \mathrm{~km}$. The receiver has been set up with a ferrite coil oriented for maximum signal amplitude of the horizontal magnetic field. After preamplification a stereo sound card computer interface with $192 \mathrm{kbit}$ sampling rate is used. The second channel is fed with the 1-s pulse of a GPS receiver. Our software reads a $170 \mathrm{~ms}$ signal train each second and extracts within the narrow MSK bandwidth ( $200 \mathrm{~Hz}$ with NRK) amplitude and phase with regard to the rising GPS-pulse flank yielding a time synchronization better than $100 \mathrm{~ns}$, corresponding to phase detection errors of $1.4^{\circ}$ at $37.5 \mathrm{kHz}$. For the amplitude the signal to noise ratio (SNR) is recorded. $\mathrm{SNR}=0 \mathrm{~dB}$ is defined by the averaged signal level received during transmitter maintenance drop outs. The time stability of both transmitters proves to be sufficient for continuous day and night monitoring not only of the amplitude but also of the phase. Our phase detection algorithm for MSK signals records phases between -90 and $+90^{\circ}$.

The NRK propagation path proceeds most of its way through the subauroral domain to the midlatitude receiver site and proves well suited to study lower ionosphere forcing from above by particle precipitation (Schmitter, 2010) and solar flares (Schmitter, 2013) as well as forcing from below by planetary wave activity (Schmitter, 2011, 2012). In this paper we concentrate on forcing by energetic electron precipitation.

\section{Modeling electron density profiles}

A well known parametrization for the conductivity of the lower ionosphere (about $60-95 \mathrm{~km}$ height) is the two parameter model of Wait and Spies (1964) with effective height $h^{\prime}$ $(\mathrm{km})$ and profile steepness $\beta(1 / \mathrm{km})$ :

$\sigma(h)=\sigma_{0} e^{\beta\left(h-h^{\prime}\right)}$,

with $\sigma_{0}=\sigma\left(h=h^{\prime}\right)=2.22 \cdot 10^{-6} \mathrm{~S} \mathrm{~m}^{-1}$.

From Eq. (1) together with the collision frequency profile $f_{\mathrm{c}}(h)=f_{0} e^{-h / H}, f_{0}=1.816 \cdot 10^{11} \mathrm{~Hz}$ and the relation between conductivity and electron density appropriate for the very low frequency range $\sigma=\epsilon_{0} \frac{\omega_{\mathrm{p}}^{2}}{f_{\mathrm{c}}}=\frac{e^{2} n_{\mathrm{e}}}{m_{\mathrm{e}} f_{\mathrm{c}}}\left(\omega_{\mathrm{p}}\right.$ : plasma frequency) we get the classic Wait and Spies (1964) electron density parametrization of the lower ionosphere:

$n_{\mathrm{e}}=n_{0} e^{-h / H} e^{\beta\left(h-h^{\prime}\right)}$,

with $n_{0}=1.43 \cdot 10^{13} \mathrm{~m}^{-3}$ and scale height $H=1 / 0.15=$ $6.67 \mathrm{~km}$ corresponding to an isothermal atmosphere with $T=230 \mathrm{~K}$.

While this loglinear electron density-height relation often is a reasonable first order approximation and intuitive with regard to the interpretation of its two parameters, it does not explain anything about the physical and chemical processes generating the profiles. We therefore want to go a step further in this respect and use reaction rate equations describing the development of the density profiles of electrons and ions. Chemical reaction based modeling has been done in the past at various levels of specification. A very detailed model of the complex D-layer chemistry is the Sodankyla Ion Chemistry (SIC) model which takes into account several hundred reactions and external forcing due to solar radiation (1-422.5 nm wavelength) as well as particle precipitation (Verronen et al., 2002). Several approaches have been made to reduce complexity to most relevant reaction types - at the cost of introducing effective reaction parameters lumping together different processes. For example: the 14 - ion + electron model of Torkar and Friedrich (1983); the 6 - ion + electron Mitra-Rowe model (Mitra and Rowe, 1972; Mitra, 1975); the 3 - ion + electron Glukhov-PaskoInan model (Glukhov et al., 1992); the electron "only" model (Rodger et al., 1998, 2007).

With regard to VLF/LF remote sensing the electron density profiles are of main interest. For this reason and also to keep the effort for the propagation calculations tolerable we use an extended version of the electron "only" model. The model is extended by taking into account electron detachment reactions. They provide an additional electron source which gains special importance around dusk and dawn, when Lyman $\alpha$ radiation is weak. This leads to the following rate equations for the electron-, positive ion- and negative ion density distributions, $n_{\mathrm{e}}, n_{-}, n_{+}\left(m^{-3}\right)$ :

$\frac{\partial n_{\mathrm{e}}}{\partial t}=q-\alpha_{\mathrm{D}} n_{+} n_{\mathrm{e}}-\beta_{n} n_{\mathrm{e}}+\left(\gamma_{n}+\rho\right) n_{-}$,

$\frac{\partial n_{-}}{\partial t}=-\alpha_{\mathrm{i}} n_{+} n_{-}+\beta_{n} n_{\mathrm{e}}-\left(\gamma_{n}+\rho\right) n_{-}$. 
Average neutrality is assumed: $n_{+}=n_{\mathrm{e}}+n_{-}$and spatial diffusion is neglected.

- $q$ : ion-pair production $\left(\mathrm{m}^{-3} \mathrm{~s}^{-1}\right)$, during daytime caused by Lyman $\alpha$ radiation and solar X-rays (from flares), during nighttime mainly by scattered Lyman $\alpha$ radiation and cosmic rays. Particle precipitation can cause additional ionization at any time. See the next subsection for a detailed discussion.

- $\alpha_{\mathrm{D}, \mathrm{i}}$ : electron (D) and negative ion (i) recombination coefficients $\left(\mathrm{m}^{3} \mathrm{~s}^{-1}\right)$

- $\beta_{\mathrm{n}}$ : three body attachment coefficient $\left(\mathrm{s}^{-1}\right)$

- $\gamma_{\mathrm{n}}, \rho$ : coefficients for electron detachment from negative ions by collision with neutrals or by photons respectively.

The reaction rates depend on the density of the reaction partners, i.e. the pressure as well as the temperature $T$ (below $100 \mathrm{~km}$ height we can assume local thermodynamic equilibrium: $\left.T=T_{\text {neutrals }}=T_{\text {ions }}=T_{\text {electrons }}\right)$. This, as well as relative abundances of ion species with different recombination coefficients, means, that the reaction rates vary with height. We use reaction rates as provided by Brekke (1997), with the exception of the attachment coefficient $\beta_{\mathrm{n}}$, where we use the more detailed relations provided in Rodger et al. (1998, 2007).

All numerical integrations are done using the classic Runge-Kutta algorithm with variable time step size $(0.1, \ldots$, $2 \mathrm{~s})$.

We now describe the ionization processes in the lower ionosphere which are included in our model.

\subsection{Forcing processes characterizing undisturbed conditions}

Before considering disturbance events the processes generating the background ionization have to be modeled. In the lower ionosphere we have continuous forcing from cosmic radiation and solar Lyman $\alpha$ extreme UV:

- cosmic radiation: the ionization rate is proportional to the neutral density $n_{\mathrm{n}}$ absorbing the radiation:

$q_{\mathrm{cosmic}}=c_{0} n_{\mathrm{n}}$,

where $c_{0}$ increases with geomagnetic latitude (1.2. $10^{-18} \ldots 1.2 \cdot 10^{-17} \mathrm{~s}^{-1}$ between 0 and $60^{\circ}$ latitude) (Nicolet and Aikin, 1960). With undisturbed conditions cosmic radiation is the main forcing process below $80 \mathrm{~km}$ height during the night. During daytime this transition height drops to $65-70 \mathrm{~km}$.

- solar Lyman $\alpha$ radiation $(121.57 \mathrm{~nm})$ on the day side and night side via scattering:
The Lyman $\alpha$ photon energy of $10.2 \mathrm{eV}$ is high enough to ionize NO but not the major species $\mathrm{O}_{2}, \mathrm{~N}_{2}$, so, with $I_{\mathrm{L}_{\alpha, \infty}}$ as the Lyman $\alpha$ intensity incident at the top of the atmosphere:

$q_{\mathrm{L}_{\alpha}}=\sigma_{\mathrm{NO}} \cdot n_{\mathrm{NO}} \cdot I_{\mathrm{L}_{\alpha, \infty}} e^{-\tau}$.

$I_{\mathrm{L}_{\alpha, \infty}}$ varies with solar activity in the range $2.5, \ldots, 5$. $10^{15}$ photons $\mathrm{s}^{-1} \mathrm{~m}^{-2}$. The optical depth integrated along the ray path with $\mathrm{O}_{2}$ as the main absorbing species is:

$\tau=\int \sigma_{\mathrm{O}_{2}} \cdot n_{\mathrm{O}_{2}} \mathrm{~d} s$.

With Nicolet and Aikin (1960) we use $\sigma_{\mathrm{NO}}=2$. $10^{-22} \mathrm{~m}^{2}$ for the ionization cross section of $\mathrm{NO}$ and $\sigma_{\mathrm{O}_{2}}=10^{-24} \mathrm{~m}^{2}$ for the absorption cross section of $\mathrm{O}_{2}$ at $121.57 \mathrm{~nm} . n_{\mathrm{O}_{2}}$ is 0.21 of the total number density at mesospheric heights. $n_{\mathrm{NO}}$ varies considerably: as the measurements of the Halogen Occultation Experiment (HALOE) of the Upper Atmosphere Research Satellite (UARS) have shown, the NO number density between 60 and $90 \mathrm{~km}$ height at undisturbed conditions during the same day can vary at least between $10^{11}$ and $10^{13} \mathrm{~m}^{-3}$. We adopt $5 \cdot 10^{12} \mathrm{~m}^{-3}$ as an average undisturbed value. The concentration of NO is significantly enhanced during particle precipitation and for hours afterwards (Barth et al., 2001; Saetre et al., 2004) - which has to be taken into account for the description of precipitation events during daylight.

\subsection{Energetic electron precipitation}

With regard to forcing processes leading to disturbed conditions we focus on electron precipitation in this paper. Electrons with energies $\gtrsim 30 \mathrm{keV}$ (Fig. 3) and protons with energies $\gtrsim 4 \mathrm{MeV}$ penetrate down into the lower ionosphere $(\lesssim 85) \mathrm{km}$. Proton precipitation are mostly confined to the polar domain, which is not crossed by the propagation path used in this investigation (Iceland - NW Germany). Different approaches to predict the auroral oval were summarized by Sigernes et al. (2011).

With Fang et al. (2008) we model the electron impact ionization rate as

$q_{\text {precip }}=Q_{0} \frac{f\left(E_{0}, \rho H\right)}{2 \Delta \epsilon H}$,

with $Q_{0}\left(\mathrm{keV} \mathrm{cm}^{-3} \mathrm{~s}^{-1}\right)$ : total vertically incident electron flux at the top of the atmosphere.

The fraction $\frac{f\left(E_{0}, \rho H\right)}{2 \Delta \epsilon H}$ stands for the ionization efficiency of an electron of (folding) energy $E_{0}$ at a specific height and temperature: 
$\rho\left(\mathrm{g} \mathrm{cm}^{-3}\right)$ : atmospheric mass density, $H=\frac{k T}{M g}$ the scale height in $\mathrm{cm}$ at temperature $T$ and with mean atmospheric molecular mass $M$, and gravitational acceleration $g$ (to ease the comparison with literature we use $\mathrm{keV}$ and $\mathrm{cm}$ units here). $\Delta \epsilon=35 \cdot 10^{-3} \mathrm{keV}$ : mean energy loss per ion pair production, $E_{0}(\mathrm{keV})$ : the folding energy of a Maxwellian electron energy spectrum:

$N(E)=\frac{Q_{0}}{2 E_{0}^{3}} E e^{-E / E_{0}}$

$N(E)$ is the differential hemispherical electron number flux $\left(\mathrm{keV} \mathrm{cm}^{-2} \mathrm{~s}^{-1}\right)$.

The numerical evaluation of the energy deposition function $f\left(E_{0}, \rho H\right)$ is described in detail in Fang et al. (2008).

We model the incident electron flux $Q_{0}\left(\mathrm{keV} \mathrm{cm}^{-2} \mathrm{~s}^{-1}\right)$ as a function of the local auroral activity $a$, geographic latitude, longitude and universal time UT according to Schmitter (2010):

$Q_{0}(a$, lat, lon, UT $)=c a w^{2} e^{-\frac{w}{2 \sigma^{2}}}$,

with $c=7.5 \cdot 10^{9}\left(\mathrm{keV} \mathrm{cm}^{-2} \mathrm{~s}^{-1}\right) . w$ is a dimensionless distance parameter with regard to the magnetic pole defined as follows: with the projected coordinates $x=r \cos$ (long), $y=r \sin$ (long), $r=r_{\mathrm{e}} \cos \left(\right.$ lat), $r_{\mathrm{e}}=6371 \mathrm{~km}$ as components of a vector $\boldsymbol{r}^{T}=(x, y)$ we define the vector $\boldsymbol{r}_{n}=$ $R_{\mathrm{UT}}\left(\boldsymbol{r}-\boldsymbol{r}_{\text {mag pole }}\right)$ which centers the coordinates at the magnetic pole and rotates according to the universal time UT using the usual 2 dimensional rotation matrix with UT expressed as rotation angle. $w=\boldsymbol{r}_{\boldsymbol{n}}{ }^{T} \mathbf{M} \boldsymbol{r}_{n}$ is the bilinear form of $\boldsymbol{r}_{n}$ scaling these coordinates to an elliptic figure with semi axes $a_{\mathrm{s}}=(1590+130 a) \mathrm{km}$ and $b_{\mathrm{s}}=(1270+100 a) \mathrm{km}$ with the scaling matrix $\mathbf{M}=\left(1 / a_{\mathrm{s}}^{2} 0 ; 01 / b_{\mathrm{s}}^{2}\right)$. With this procedure the auroral oval is fixed relative to the longitude of the sun with the more intensive part at local midnight. As an example of this type of distribution function see Fig. 4. Our approach for modeling the auroral oval distribution can be compared to that described in Semeniuk et al. (2008). They use poleward and equatorward boundaries to parametrize the auroral oval. Our formulation was inspired by the POES auroral oval data which made use of an auroral activity parameter (this product is replaced by the Ovation-Prime-model, www.swpc.noaa.gov/models since 14 February 2014). In contrast to the POES global (hemispheric) activity our activity parameter quantifies the local precipitation intensity $Q_{0}$.

The constant $c=7.5 \cdot 10^{9}\left(\mathrm{keV} \mathrm{cm}^{-2} \mathrm{~s}^{-1}\right)$ is defined such that the elliptic shapes according to the NOAA POES statistical auroral activity maps (www.swpc.noaa.gov/pmap/) are reproduced and by integrating $Q_{0}$ over the hemispheric area the total hemispheric power input $P$ at auroral activity index $a=0, \ldots, 10$ results in accordance with the NOAA POES data (www.swpc.noaa.gov/ftpdir/lists/hpi/). It is roughly $P=e^{a / 2} \mathrm{GW}$ (GigaWatt).

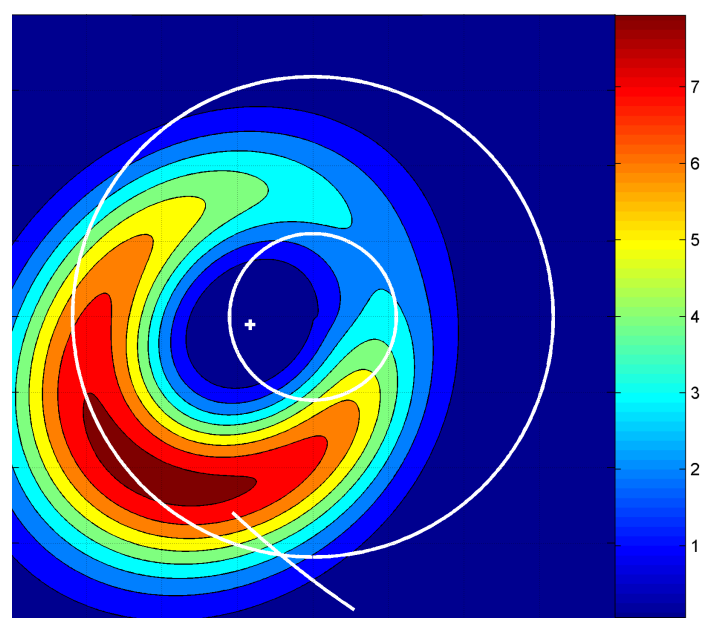

Figure 4. The auroral oval distribution function for 03:00 UT and POES activity level 10 . The two rings mark 60 and $80^{\circ}$ geographic latitude. The cross left from the North Pole (center of the rings) is the magnetic south pole. Colorbar: $\mathrm{erg} \mathrm{cm}^{-2} \mathrm{~s}^{-1}=\mathrm{mW} \mathrm{m}^{-2}$. The VLF propagation path from Iceland to NW Germany $(2210 \mathrm{~km}$ distance) is also marked.

The local auroral activity $a$ at time $\mathrm{t}$ is parametrized proportional to the VLF/LF amplitude dip:

$a(t)=c_{\mathrm{dB}}\left(\mathrm{amp}_{\text {undisturbed }}-\mathrm{amp}_{\text {disturbed }}(t)\right)$

The proportionality constant is measured in auroral activity units per signal amplitude drop $(\mathrm{dB})$.

\subsection{Constraining the precipitation distribution function using Swarm FAC data}

Because the definition of the electron energy input distribution function $Q_{0}$ is a main result of this paper we discuss it in some more detail. For a better understanding we approximate the oval semi axes parameters $a_{\mathrm{s}}$ and $b_{\mathrm{s}}$ by the circular average $\gamma=1380+115 a \mathrm{~km}$ and get

$Q_{0} \cong c a\left(\frac{d}{\gamma}\right)^{4} e^{-\left(\frac{d}{\gamma}\right)^{2} / 2 \sigma^{2}}$,

where $d$ is the distance from the magnetic pole for the geographic point in question. At at $d_{\max }=2 \gamma \sigma$ the function attains its maximum $Q_{0}\left(d_{\max }\right)=c a(2 \sigma)^{4} / e^{2}(e=\exp (1))$. The dimensionless width $\sigma$ is parametrized by $\sigma=\sigma_{0}+$ $\sigma_{1} a\left(1+0.25 \cos \left(\phi_{\mathrm{UT}}\right)\right)$ with $\phi_{\mathrm{UT}}=0$ at local midnight.

Assuming that electron precipitation is confined to the range of significant field aligned currents we constrain $Q_{0}$ using Swarm FAC data, compare Figs. 5 and 6. Figure 5 shows the FAC distribution as recorded by the Swarm A,B,C satellites during their orbits between 0:00 and 4:00 UT on 12 April 2014. Figure 6 shows the FACs along a nearly meridional cut through the auroral oval at $5^{\circ} \mathrm{W}$ longitude between 50 and $85^{\circ} \mathrm{N}$ latitude. Displayed in this figure are the results 


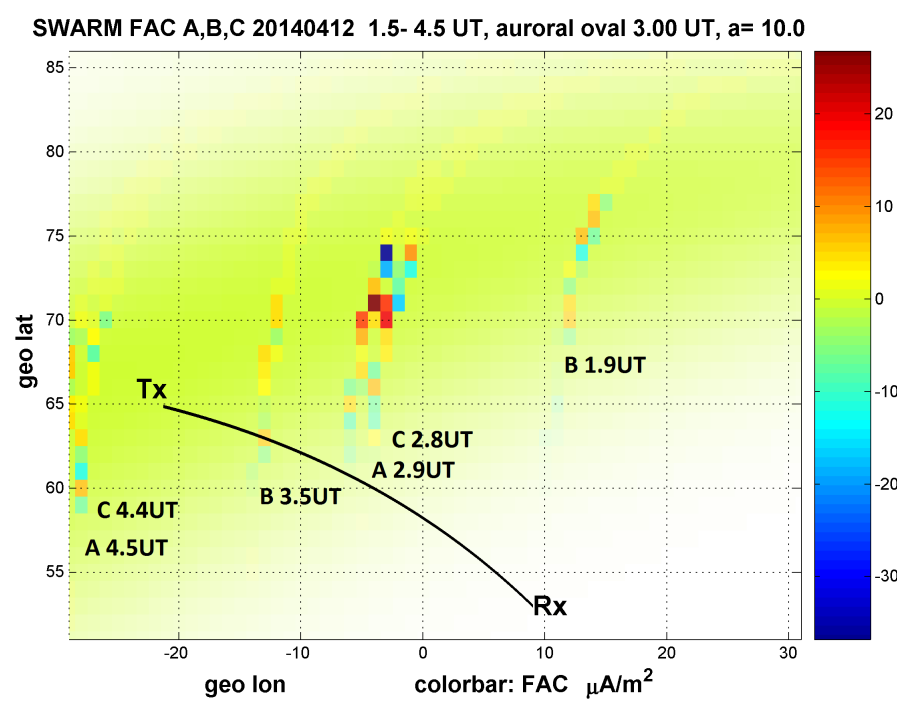

Figure 5. Field aligned currents from Swarm satellites A, B, C on day 12 April 2014 from orbits between 1.9 and $4.5 \mathrm{~h}$ together with the VLF propagation path Iceland-NW Germany. Underlying (green) the auroral oval distribution function according to Fig. 4 is shown.

from the satellites $\mathrm{A}$ and $\mathrm{C}$ which are flying side by side and cross the indicated latitudes in about $12 \mathrm{~min}$. Their separation according to the specifications is $1.4^{\circ}$ in geographic longitudes corresponding to $78 \mathrm{~km}$ at $60^{\circ} \mathrm{N}$. A time delay of max. $10 \mathrm{~s}$ along their orbit corresponds to max. $70 \mathrm{~km}$ distance in latitude. At the time of preparation of this paper the combined FAC data evaluation from both satellites was not available. The currents are significant between $61^{\circ} \mathrm{N}$ and $76^{\circ} \mathrm{N}$ at a common longitude of $\cong 5^{\circ} \mathrm{W}$, which corresponds to a local auroral oval width of $1800 \mathrm{~km}$. On the average FACs are negative in the equatorward half of the auroral oval and positive on the poleward half (by definition the FACs are parallel to the magnetic field lines and point inwards at northern latitudes). In detail however the $20 \mathrm{~s}$ low passed data exhibit 5 periods of different FAC domains across the auroral oval, each of a width of about $360 \mathrm{~km}$. With regard to the FAC evaluation method see Ritter et al. (2013).

Now let $d_{\mathrm{p}}, d_{\mathrm{e}}$ be the distances from the magnetic pole of the poleward and equatorward FAC limit points $\left(76^{\circ} \mathrm{N}\right.$, $\left.5^{\circ} \mathrm{W} ; 61^{\circ} \mathrm{N}, 5^{\circ} \mathrm{W}\right)$ for the parallel overflight of Swarm satellites $\mathrm{A}$ and $\mathrm{C}$ between 2.77 and $2.93 \mathrm{~h}$ on the day 12 April 2014. Requiring $Q_{0}\left(d_{\mathrm{p}}\right)=Q_{0}\left(d_{\mathrm{e}}\right) \cong 0$ we numerically find for an activity $a=10 \sigma_{0}=0.2$ and $\sigma_{1}=0.02$ as consistent parameters for the width $\sigma=\sigma_{0}+\sigma_{1} a(1+$ $\left.0.25 \cos \left(\phi_{\mathrm{UT}}\right)\right), \mathrm{UT}=2.85 \mathrm{~h}$. For the resulting shape of the $Q_{0}$-function see Figs. 4 and 5. An investigation of other precipitation events is necessary to test the range of validity of the parametrization of the electron input distribution function.

With all the ionization sources and reaction rates defined by the rate equations (Eqs. 3 and 4) can be integrated. The

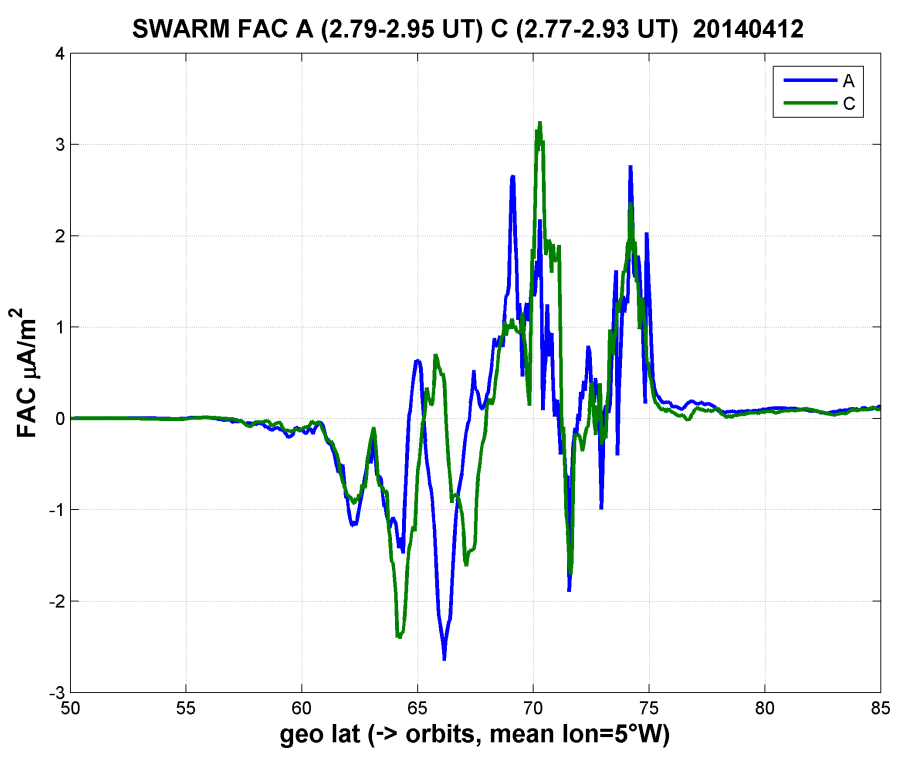

Figure 6. Field aligned currents from Swarm satellites A and C flying side by side, 12 April $2014,2.8-2.9 \mathrm{~h}$ at about $5^{\circ} \mathrm{W}$ longitude (Atlantic, north of Scotland), $20 \mathrm{~s}$ low pass filtered. The data correspond to the (A, C) orbits near the center of Fig. 5. This figure and Fig. 5 are based on Swarm Level 2 data.

resulting electron density $n_{\mathrm{e}}$ as function of time, height and position along the radio wave propagation path is the essential input for the propagation calculation. The $c_{\mathrm{dB}}$ parameter, Eq. (11), is adjusted to yield the best possible fit of the calculated signal amplitude to the disturbed recorded signal amplitude.

\section{Propagation calculations}

For frequencies below the plasma frequency $\sqrt{\frac{e^{2} n_{\mathrm{e}}}{\epsilon_{0} m_{\mathrm{e}}}}$ the space between the conducting Earth ground and the ionosphere behaves like a leaky waveguide. For the VLF/LF range the diffuse upper waveguide boundary is formed by the lower ionosphere (60-90 km height). Propagation calculation in our case is the task to calculate at a ground based receiver position the signal field amplitude and phase of a ground based transmitter (vertical electric and horizontal magnetic field components). Besides transmitter radiated power and antenna characteristics the essential input to the calculation are the conductivities of the waveguide along the great circle propagation path. We use the LWPC (Long Wave Propagation Capability) code (Ferguson, 1998) for this purpose. It includes a world wide map of the ground conductivities. For the ionospheric conductivity $\left(\sigma=\frac{e^{2} n_{\mathrm{e}}}{m_{\mathrm{e}} f_{\mathrm{c}}}\right)$ the collision frequency and electron density height profiles along the path have to be provided. The collision frequency height profile is usually assumed to be constant along the path: $f_{\mathrm{c}}(h)=$ $f_{0} e^{-h / H}, f_{0}=1.816 \cdot 10^{11} \mathrm{~Hz}, H=6.67 \mathrm{~km}$. It may how- 

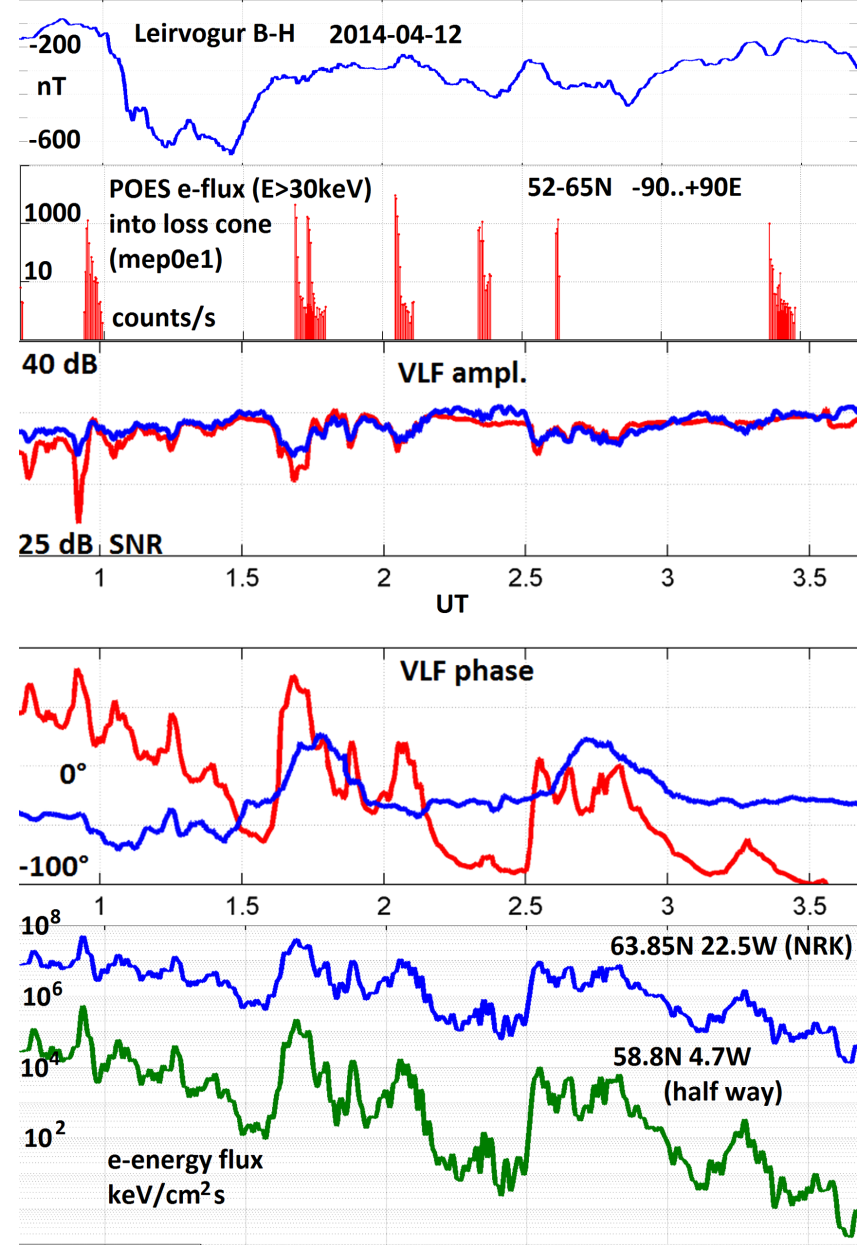

Figure 7. 12 April 2014: From top to bottom: Leirvogur magnetometer data (horizontal magnetic field component); energetic electron precipitation data from the mep0e1-sensors of 5 POES/Metop satellites that had overflights at the time (UT hours) and within the area indicated; recorded (blue) and modeled (red) VLF/LF amplitude and phase data during pulsed electron precipitation along the propagation path; electron kinetic energy input flux $Q_{0}$ (Eq. 10) between 0.7 and $3.7 \mathrm{~h}$ on 12 April 2014 derived from VLF propagation modeling exemplary for two segments along the propagation path (at the transmitter and half way to the receiver) using a Maxwellian electron energy spectrum with a folding energy of $40 \mathrm{keV}$. The Leirvogur magnetometer and VLF/LF data display a zoomed part of Fig. 8 .

ever be modulated by gravity or planetary waves (Schmitter, 2012). The electron density $n_{\mathrm{e}}(h)$ at height $h$ changes along the path with sun zenith angle, activity of the sun (e.g. solar flares, Schmitter, 2013) and because of local forcing, e.g. particle precipitation.

The propagation path is divided in $50 \mathrm{~km}$ segments. Each segment is provided with the proper electron density height profile (integrated from the rate equations, Sect. 3) for the time step and the location in question. Propagation calculations are done in one minute intervals (however the integra- tion of the rate equations yielding the electron density profiles has to use much smaller step sizes, typically $0.1-2 \mathrm{~s}$ ).

LWPC then does a full wave calculation resulting in the vertical electric field amplitude and phase at the receiver site, the horizontal magnetic field data being directly proportional. To allow comparisons with our recorded data amplitude results are displayed in $\mathrm{dB}$ above the noise level, phases in degree, compare Fig. 7, panels 3 and 4 from top.

\section{Results}

In Fig. 7 as an example we see the course of the VLF/LF amplitude and phase (blue) during pulsed electron precipitation (panels 3 and 4 from top, zoomed portion of Fig. 8, bottom panel) together with our model calculation (red) where the ionization by energetic electrons is accounted for by a Maxwellian spectrum with $40 \mathrm{keV}$ folding energy with impact ionization parametrization from Fang et al. (2008) and an intensity and space distribution according to the auroral oval model function $Q_{0}$, Eq. (10), which accounts for the precipitation intensity distribution in space and time, as described in Sects. 3.2 and 3.3. For comparison the energetic electron $(E>30 \mathrm{keV})$ flux into the loss cone as observed by the low orbit polar orbiters POES15,16,18,19 and Metop02 satellites during their overflights (panel 2 from top, mep0e1 data) and the Leirvogur magnetometer data (top panel) are shown. Within $52-65^{\circ} \mathrm{N}$ latitude and -90 to $+90^{\circ} \mathrm{E}$ longitude encompassing the propagation path of the POES/Metop satellite data confirm sporadically energetic electron precipitation during the time of the VLF events (there was no enhanced proton level at that time). The magnetometer data confirm a synchronous ionospheric current activity in the vicinity of the NRK transmitter (Leirvogur is situated about $50 \mathrm{~km} \mathrm{NW}$ of the NRK transmitter). In the non zoomed Fig. 8, top panel, the difference to the undisturbed situation is more clearly to be seen.

There are two parameters in the model that are fitted to the data: the proportionality constant $c_{\mathrm{dB}}$ (auroral activity per signal amplitude drop (dB)) yielding the activity parameter $a(t)=c_{\mathrm{dB}}\left(\mathrm{amp}_{\text {undisturbed }}-\mathrm{amp}_{\text {disturbed }}(t)\right)$, and the folding energy $E_{0}$ of the electron energy spectrum $(40 \mathrm{keV}$ in our example case). $c_{\mathrm{dB}}$ has been adjusted for best fit of the modeled signal amplitude to the disturbed recorded signal amplitude. Changing the folding energy by more than -5 or $+10 \mathrm{keV}$ degenerates the fit quality significantly.

Level 2 data from the Swarm mission are used to identify the spatial extension of field aligned current densities (FACs). With this information the precipitation boundaries are assessed and the electron input distribution function $Q_{0}$ has been constrained.

The FAC constrained spatial distribution of the precipitation along the propagation path together with the VLF/LF amplitude variations yields $c_{\mathrm{dB}}=0.2$ (auroral activity units per $\mathrm{dB}$ signal amplitude drop) at $37.5 \mathrm{kHz}$ and supports the 

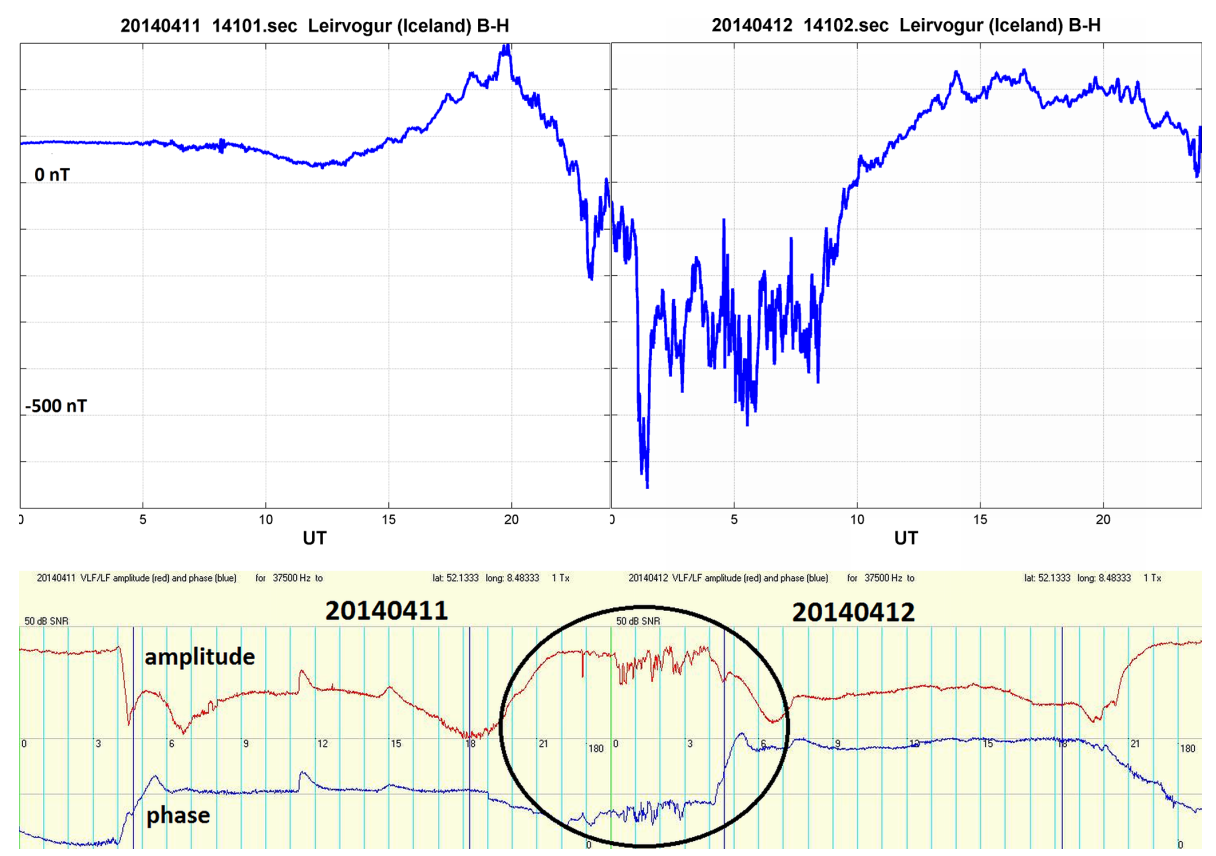

Figure 8. Days 11 and 12 of April 2014: effect of a series of energetic electron precipitation bursts with regard to VLF/LF signals. Lower panel: VLF amplitude (dB SNR, red) and phase (deg, blue). The top panel displays the LEIRV magnetometer response reflecting ionospheric current fluctuations during the substorm condition starting in the evening hours of 11 April 2014. (LEIRV: Leirvogur, Iceland, 50 km NW of the NRK transmitter). The humps in the VLF/LF signal during daytime of 11 April 2014 are solar flare responses. Sunrise and sunset are marked by vertical lines.

assumption of an $E_{0}=40 \mathrm{keV}$ Maxwellian electron spectrum in the model calculations. $c_{\mathrm{dB}}$ is expected to be constant in our modeling scheme, so that after calibration an application with regard to other electron precipitation events can concentrate on the determination of $E_{0}$, which can be a function of time.

As the main modeling result the energy input from electron precipitation as a function of time is available for each of the $50 \mathrm{~km}$ segments along the VLF propagation path $\left(Q_{0}\right.$ distribution function). For two segments (near the transmitter and half ways along the propagation path to the receiver) the electron input energy flux results are shown in Fig. 7, bottom panel. The maximum energy flux rate at the transmitter coordinates $64^{\circ} \mathrm{N} 22.5^{\circ} \mathrm{W}$ is $5 \cdot 10^{7} \mathrm{keV} \mathrm{cm}^{-2} \mathrm{~s}^{-1}=$ $0.08 \mathrm{~mW} \mathrm{~m}^{-2}$. Half way to the receiver coordinates $\left(58.8^{\circ} \mathrm{N}\right.$, $4.7^{\circ} \mathrm{W}$ ) the flux is reduced by two orders of magnitude. The ionization rate vs. height characteristics for the reported fluxes and $E_{0}=40 \mathrm{keV}$ can be read from Fig. 3 (maximum: $8 \cdot 10^{8} \mathrm{~m}^{-3} \mathrm{~s}^{-1}$ at $78 \mathrm{~km}$ height).

The variation of the $Q_{0}$ function (Fig. 7, bottom panel) reflects the course of the disturbed VLF/LF signal amplitude because we define the activity parameter $a(t)$ (which controls the electron input) proportional to the signal amplitude, Eq. (11). The constant $c_{\mathrm{dB}}$ is chosen for a good fit of recorded and modeled VLF/LF signal amplitude data. The modeled phase also has to reflect the $a(t)$ course (here in an inverted way) because it is an input into the propagation calculation, however there is only little correlation to the recorded phase. This can be understood if we take into account that signal phases in contrast to amplitudes are sensitive to all kinds of effects along the propagation path in a cumulative way.

With regard to the spatial resolution of the derived flux values we recall that the main part of the electromagnetic energy that is transferred from a transmitter to a receiver is contained in the first Fresnel zone, an ellipsoid encompassing the propagation path with an extension orthogonal to the propagation path of the order of one wavelength $(\lambda=8 \mathrm{~km}$ for $37.5 \mathrm{kHz})$ near the transmitter and the receiver and a maximum extension of $0.5 \sqrt{\lambda d}=66 \mathrm{~km}$ at half way (Tx-Rx distance $d=2210 \mathrm{~km}$ ). So with a segment length of $50 \mathrm{~km}$ along the propagation path the spatial resolution of our VLF/LF remote sensing model, i.e. the averaging area, varies between $8.50 \mathrm{~km}^{2}$ near to the transmitter and near to the receiver and $66 \cdot 50 \mathrm{~km}^{2}$ at half way.

\section{Conclusions}

The main objective of the work described in this paper is to advance our VLF/LF propagation model by including the effect of electron particle precipitation. The extended model allows for the characterization of Maxwellian electron energy spectra along the VLF/LF propagation path by using data from continuous VLF/LF remote sensing and field aligned current density data from the new Swarm mission. The cur- 
rent status of the modeling efforts has been demonstrated with regard to electron precipitation bursts during a moderate substorm condition on 12 April $2014(\mathrm{Kp}=5$, min. $\mathrm{DST}=-80 \mathrm{nT}$, min. AL $=-700 \mathrm{nT}$ ). Signal amplitude disturbances along a $37.5 \mathrm{kHz}$ radio propagation path from Iceland $\left(63.9^{\circ} \mathrm{N}, 22.5^{\circ} \mathrm{W}\right)$ to a midlatitude site $\left(52^{\circ} \mathrm{N}, 8^{\circ} \mathrm{E}\right)$ have been modeled successfully and an electron energy input distribution function has been derived. Future work intends to model many different precipitation events and to further validate the parametrization of the electron input distribution function. For this purpose our software has to be optimized with regard to speed to allow for faster modeling cycles. The space time characterization of electron energy spectra can help to quantify the effectiveness of energetic electron precipitation with regard to $\mathrm{NO}_{x}$ production and ozone depletion at mesospheric heights, underlining the importance of energetic electron precipitation as a part of solar influence on the atmosphere and the climate system (Andersson et al., 2014).

Acknowledgements. Swarm Level 2 data have been provided by the European Space Agency and the POES/Metop data have been provided by the US NOAA National Geophysical Data Center.

Edited by: M. Förster

Reviewed by: two anonymous referees

\section{References}

Andersson, M. E., Verronen, P. T., Rodger, C. J., Clilverd, M. A., and Seppaelae, A.: Missing driver in the SunEarth connection from energetic electron precipitation impacts mesospheric ozone, Nat. Comm., 5, 5197, doi:10.1038/ncomms6197, 2014.

Barth, C. A., Baker, D. N., Mankoff, K. D., and Bailey, S. M.: The northern auroral region as observed in nitric oxide, Geophys. Res. Lett., 8, 1463-1466, doi:10.1029/2000GL012649, 2001.

Brekke, A.: Physics of the upper polar atmosphere, John Wiley \& Sons, New York, USA, 1997.

Carson, B. R., Rodger, C. J., and Clilverd, M. A.: POES satellite observations of EMIC-wave driven relativistic electron precipitation during 1998-2010, J. Geophys. Res.-Space, 118, 232-243, doi:10.1029/2012JA017998, 2012.

Clilverd, M. A., Seppaelae, A., Rodger, C. J., Thomson, N. R., Lichtenberger, J., and Steinbach, P.: Temporal variability of the descent of high-altitude NOX inferred from ionospheric data, J. Geophys. Res., 112, A09307, doi:10.1029/2006JA012085, 2007.

Cummer, S. A., Bell, T. F., and Inan, U. S.: VLF remote sensing of the auroral electrojet, J. Geophys. Res., 101, 5381-5389, 1996.

Cummer, S. A., Inan, U. S., and Bell, T. F.: Ionospheric D region remote sensing using VLF radio atmospherics, Radio Sci., 33, 1781-1792, doi:10.1029/98RS02381, 1998.

Fang, X., Randal, C. E., Lummerzheim, I. D., Solomon, S. C., Mills, M. J., Marsh, D. R., Jackman, C. H., Wang, W., and Lu, G.: Electron impact ionization: A new parameterization for $100 \mathrm{eV}$ to $1 \mathrm{MeV}$ electrons, J. Geophys. Res., 113, A09311, doi:10.1029/2008JA013384, 2008.
Ferguson, J. A.: Computer Programs for Assessments of LongWavelength Radio Communications, Version 2.0, Technical Document, SPAWAR Systems Center, San Diego, USA, available at: http://www.dtic.mil/dtic/tr/fulltext/u2/a350375.pdf (last access: 12 May 2015), 1998.

Glukhov, V. S., Pasko, V. P., and Inan, U. S.: Relaxation of transient lower ionospheric disturbances caused by lightningwhistler-induced electron precipitation bursts, J. Geophys. Res., 97, 16971-16979, 1992.

Mitra, A. P. and Rowe, J. N.: Ionospheric effects of solar flares - VI. Changes in D-region ion chemistry during solar flares, J. Atmos. Sol.-Terr. Phy., 34, 795-806, 1972.

Mitra, A. P.: D-region in disturbed conditions, including flares and energetic particles, J. Atmos. Sol.-Terr. Phy., 37, 895-913, 1975.

Nicolet, M. and Aikin, A. C.: The Formation of the D Region of the Ionosphere, J. Geophys. Res., 65, 1469-1483, 1960.

Ohtani, S., Wing, S., Newell, P. T., and Higuchi, T.: Locations of nights' side precipitation boundaries relative to R2 and R1 currents, J. Geophys. Res., 115, A10233, doi:10.1029/2010JA015444, 2010.

Ritter, P., Lühr, H., and Rauberg, J.: Determining field-aligned currents with the Swarm constellation mission, Earth Planets Space, 65, 1285-1294, 2013.

Rodger, C. J., Molchanov, O. A., and Thomson, N. R.: Relaxation of transient ionization in the lower ionosphere, J. Geophys. Res., 103, 6969-6975, 1998.

Rodger, C. R., Clilverd, M. A., Thomson, N. R., Gamble, R. J., Seppaelae, A., Turunen, E., Meredith, N. P., Parrot, M., Sauvaud, J. A., Berthelier, J. J.: Radiation belt electron precipitation into the atmosphere: Recovery from a geomagnetic storm, J. Geophys. Res., 112, A11307, doi:10.1029/2007JA012383, 2007.

Saetre, C., Stadsnes, J., Nesse, H., Aksnes, A., Petrinec, S. M., Barth, C. A., Baker, D. N., Vondrak, R. R., and Ostgaard, N.: Energetic electron precipitation and the $\mathrm{NO}$ abundance in the upper atmosphere: A direct comparison during a geomagnetic storm, J. Geophys. Res., 109, A09302, doi:10.1029/2004JA010485, 2004.

Salmi, S.-M., Verronen, P. T., Thölix, L., Kyrölä, E., Backman, L., Karpechko, A. Yu., and Seppälä, A.: Mesosphere-to-stratosphere descent of odd nitrogen in February-March 2009 after sudden stratospheric warming, Atmos. Chem. Phys., 11, 4645-4655, doi:10.5194/acp-11-4645-2011, 2011.

Semeniuk, K., McConnell, J. C. , Jin, J. J. Jarosz, J. R., Boone, C. D., and Bernath, P. F.: $\mathrm{N}_{2} \mathrm{O}$ production by high energy auroral electron precipitation, J. Geophys. Res., 113, D16302, doi:10.1029/2007JD009690, 2008.

Schmitter, E. D.: Remote auroral activity detection and modeling using low frequency transmitter signal reception at a midlatitude site, Ann. Geophys., 28, 1807-1811, doi:10.5194/angeo-281807-2010, 2010.

Schmitter, E. D.: Remote sensing planetary waves in the midlatitude mesosphere using low frequency transmitter signals, Ann. Geophys., 29, 1287-1293, doi:10.5194/angeo-29-1287-2011, 2011.

Schmitter, E. D.: Data analysis of low frequency transmitter signals received at a midlatitude site with regard to planetary wave activity, Adv. Radio Sci., 10, 279-284, doi:10.5194/ars-10-279-2012, 2012.

Schmitter, E. D.: Modeling solar flare induced lower ionosphere changes using VLF/LF transmitter amplitude and phase ob- 
servations at a midlatitude site, Ann. Geophys., 31, 765-773, doi:10.5194/angeo-31-765-2013, 2013.

Schmitter, E. D.: Remote sensing and modeling of lightning caused long recovery events within the lower ionosphere using VLF/LF radio wave propagation, Adv. Radio Sci., 12, 241-250, doi:10.5194/ars-12-241-2014, 2014.

Sigernes, F., Dyrland, M., Brekke, P., Chernouss, S., Lorentzen, D. A., Oksavik, K., and Deehr, C. S.: Two methods to forecast auroral displays, J. Space Weather, 1, A03, doi:10.1051/swsc/2011003, 2011.

Thorne, R. M.: A cause of dayside relativistic electron possible precipitation events, J. Atmos. Sol.-Terr. Phy., 36, 635-645, doi:10.1016/0021-9169(74)90087-7, 1974.

Thorne, R. M., Li, W., Ni, B., Ma, Q., Bortnik, J., Chen, L., Baker, D. N., Spence, H. E., Reeves, G. D., Henderson, M. G., Kletzing, C. A., Kurth, W. S., Hospodarsky, G. B., Blake, J. B., Fennell, J. F., Claudepierre, S. G., and Kanekal, S. G.: Rapid local acceleration of relativistic radiation-belt electrons by magnetospheric chorus, Nature, 504, 411-414, doi:10.1038/nature12889, 2013.
Torkar, K. and Friedrich, M.: Tests of an Ion-Chemical Model of the D- and Lower E-Region, J. Atmos. Terr. Phys., 45, 369-385, 1983.

Verronen, P. T., Turunen, E., Ulich, T., and Kyrola, E.: Modelling the effects of the October 1989 solar proton event on mesospheric odd nitrogen using a detailed ion and neutral chemistry model, Ann. Geophys., 20, 1967-1976, 2002, http://www.ann-geophys.net/20/1967/2002/.

Wait, J. R. and Spies, K. P.: Characteristics of the Earthionosphere waveguide for VLF radio waves, NBS Tech. Note 300, available at: http://nova.stanford.edu/ vlf/IHY_Test/ Tutorials/SfericsAndTweaks/Papers/Wait1964f.pdf (last access: 12 May 2015), 1964. 